\title{
Cement-based materials destruction under the action of deicing salts
}

\author{
Ekaterina Potapova ${ }^{1}$ and Ivan Korchunov ${ }^{1, *}$ \\ ${ }^{1}$ D. Mendeleev University of Chemical Technology of Russia, Russian Federation
}

\begin{abstract}
The results of chloride ions with aqueous solution penetrating into the cement structure were determined with the colorimetric method. Some tendencies of chloride solutions migration in different conditions were established. The article suggests the possible ways of the prevention of destructive processes occur during the excessive pore solution saturation in cement matrix with chloride ions.
\end{abstract}

\section{Introduction}

The steel reinforcement corrosion is a fundamental element for concrete structures considering the durability of materials. It is especially notable in the conditions of regular sea water exposure. Concretes often suffer from corrosion under the action of chloride salts solutions. It is known that the high-alkaline environment of the cement matrix prevents the occurrence of steel reinforcement corrosion processes in the reinforced concrete structures. However, chloride ions actively interact with calcium hydroxide, reducing the $\mathrm{pH}$ level in pore solution [1,2]. There is an oxide film destruction on the surface of the reinforcement and, as a consequence, the beginning of corrosion. Chloride salts could be contained in the concrete mixture or penetrate from the environment. It is known $[3,4]$ that chloride ions can be bound by the phases of cement, forming new phases in the structure. Besides, they can stay in the pore solution of the cement matrix. Bounded chlorides do not cause corrosion of the embedded steel reinforcement. On the contrary, free chloride ions in the pore solution reduce the $\mathrm{pH}$ of the cement environment. To reduce the fluid migration into capillaryporous materials (concretes), it is necessary to limit the porosity of the material to ensure high durability of the material and its resistance in aggressive environments.

It is known that the slag has a good ability to absorb chloride ions (which largely depends on the $\mathrm{CaO} / \mathrm{SiO}_{2}$ ratio, its content and impurities contained) [5]. This predetermined the usage of partially replaced cements with mineral additives. High binding of dangerous chloride ions capacity allows to save the reinforcement and prolong the service life of the material. The major minerals, providing a good $\mathrm{Cl}^{-}$accession, are the products of the calcium aluminate $\left(\mathrm{C}_{3} \mathrm{~A}\right)$ hydration. Among them are monohydrosulfoaluminate $\left(\mathrm{AF}_{\mathrm{m}}\right)$ and ettringite $\left(\mathrm{AF}_{\mathrm{t}}\right)$.

\footnotetext{
* Corresponding author: korchunov94@bk.ru
} 


\section{The materials and research methods}

There are several methods of free and bound chloride ions determination in concrete. The most practical are the colorimetric methods using $\mathrm{AgNO}_{3}$, allowing to measure the chlorides penetration depth $[6,7]$. However, there is no consensus among scientists on the methodology of the experiment.

Colorimetric determination of the chlorides penetration depth into surface cracks and pores is especially important for understanding the possibility of reinforcement using. It is known that the main sources of chlorides penetrating into the pores are sea water or deicing salts. The source of chlorides in this research was a $5 \% \mathrm{NaCl}$ aqueous solution, where the samples were saturated before frost resistance determination [8]. The ordinary cement CEM I 42,5 $\mathrm{N}$ (Cement 1 ) and partly replaced cement with $10 \%$ slag (with $\mathrm{CaO} / \mathrm{SiO}_{2}$ ratio = 1,02 ) by mass (the Cement 2) were used in this work.

In 1970 Collepardi colorimetric method that distinguishes free chloride from bounded one was used in Italy to determine the penetration of chlorides in the concrete structure [9]. This method is based on spraying fluoresceine $(1 \mathrm{~g} / \mathrm{l}$ in a solution of $70 \%$ ethyl alcohol in water) on the surface, followed by treatment with an aqueous solution of silver nitrate $(0.1$ $\mathrm{M} \mathrm{AgNO}_{3}$ ). In the absence of chlorides or only in the presence of bound chlorides, the concrete surface becomes pink, and in the presence of free $\mathrm{AgCl}$ chloride, a white precipitate is formed. Another area quickly darkens due to the photochemical process in natural light.

$$
\left.2 \mathrm{AgNO}_{3}+\mathrm{NaCl}=>\mathrm{AgCl} \downarrow \text { (white }\right)+\mathrm{NaNO}_{3}
$$

A simpler way to measure the penetration depth of chloride ions using only silver nitrate is based on the chemical interaction between silver ions $\mathrm{Ag}^{+}$and $\mathrm{Cl}^{-}$chloride ions of white sediment. If the colorimetric method is applied to concrete structures exposed to chlorides, besides the formation of white sediment, an additional deposition reaction occurs. That means, after the formation of calcium hydroxide $\mathrm{Ca}(\mathrm{OH})_{2}$, as a result of hydration of cement, hydroxide ions in the voids give a brown precipitate after the reacting with silver ions.

According to Collepardi, Kim and others $[9,10]$ it is necessary to pre-treat the surface (chip) of the sample with $10 \% \mathrm{NaOH}$ solution before colorimetric determination of free chloride ions in the cement. It is important to maintain the surface $\mathrm{pH}$ about 12 to avoid inaccuracies, as in the presence of carbonates, the reaction also leads to the formation of a white precipitate, which confirms the reaction (2). Thus, carbonized concrete may mislead the tester in the presence of such a color even without chlorides.

$$
\mathrm{Ag}^{+} \mathrm{CO}_{2}^{-}=>\mathrm{AgCO}_{3} \text { (white) }
$$

The presence of free chlorides determination is recommended to do no later than 2 days after the frost tests. Later tests do not give positive results, probably due to the high activity of chloride ions and their ability to form compounds with cement phases (for example, $\mathrm{C}_{3} \mathrm{~A} \cdot \mathrm{CaCl}_{2} \cdot 10 \mathrm{H}_{2} \mathrm{O}$, Friedel salt [11], bound chloride adsorbed on C-S-H and others). Frost resistance was determined in accordance with the current Russian standard [8] after a presaturation in $5 \% \mathrm{NaCl}$ environment conditions.

\section{Results and discussions}

In the process of research, it was found, that the using of fluoresceine method it is very problematic to achieve a clear penetration boundary. Moreover, it is very important to follow the certain sequence of reagents application spraying, which complicates the process 
of colorimetric determination. Multicomponent methods give a significant error, forming only an approximate darkening zone, which makes it difficult to determine the real field of chloride penetration. Therefore, it was decided to use a simplified method for determining chloride ions penetration, implying the use of silver nitrate concentration of $0.1 \mathrm{M} / \mathrm{l}$ with pretreatment of the sample`s test surface with $10 \% \mathrm{NaOH}$ solution to avoid colorimetric mistakes links with carbonization depth.

Photocolorimetric analysis is still used to measure the depth of penetration of chlorides into the structure of capillary-porous bodies. The average penetration depth is calculated with the following equation:

$$
\mathrm{X}_{\mathrm{D}}=\frac{S_{C l^{-}}}{S} \times \mathrm{L}
$$

where $\mathrm{S}_{\mathrm{Cl}}{ }^{-}$- is the area affected by chlorides, $\mathrm{S}$ and $\mathrm{L}$ are the area and thickness of the sample, respectively.

This method was used to study the penetration of chlorides into the structure of cements Cement 1 and Cement 2 under conditions of static saturation, as well as after a certain number of freezing and thawing cycles. Some of the studied parameters are presented in table 1.

Table 1. Research materials properties

\begin{tabular}{|c|c|c|c|c|}
\hline \multirow{2}{*}{ Name } & $\begin{array}{c}\text { Number of } \\
\text { freezing-thawing } \\
\text { cycles }\end{array}$ & $\begin{array}{c}\text { Strength decreasing } \\
\text { under the action of } \\
\text { freezing and } \\
\text { thawing, \% }\end{array}$ & $\begin{array}{c}\mathrm{Cl}^{-} \text {penetration } \\
\text { depth } \mathrm{X}_{\mathrm{D}}, \%\end{array}$ & \multirow{2}{*}{ Porosity, \% } \\
\cline { 2 - 4 } Cement 1 & - & $-0,1$ & 48,9 & \multirow{2}{*}{10,1} \\
\cline { 2 - 4 } Cement 2 & 20 & $-25,4$ & 63,4 & \multirow{2}{*}{12,2} \\
\cline { 2 - 4 } & - & $-1,3$ & 30,07 & 81,2 \\
\hline
\end{tabular}

Based on the data obtained, it can be concluded that the ions diffusion into the cement structure with salt solution proceeds more intensively when applying freezing-thawing cycles, rather than by means of capillary suction only, when samples are immersed in $\mathrm{NaCl}$ solution at room temperature (control samples) [12,13]. These could be explained by the rule of mass transfer in capillary-porous bodies. The liquid-phase located in the pore spaces tends to arrive at a cooler surface, thereby a gradient of ion migration inside the samples (during defrosting) and out (during cooling) are creating in accordance with this rule. This process explains the absence of a chloride penetration front boundary into the cement structure for freezing-thawing samples (Fig.2), but not for control samples, where boundary of chloride penetration is clear. Moreover, the composition containing slag in an amount of $10 \%$ is characterized by a greater penetration depth of chlorides than Cement 1 but is provided higher frost resistance (see Table 1). Previously noted, that the slag phases have a good binding capacity of chloride ions, but, of course, the amount of the limit binding capacity depends on the concentration of $\mathrm{Cl}^{-}$ions in the solution. Cement 2 in general is characterized by greater porosity. This porosity is not only capillary one, but also airinvolved one. It could explain both the increase in frost resistance of the sample and the increase in migration of chloride ions. Frost resistance of such compositions is higher. The results are presented in Fig. 1 and Fig.2. he $X_{D}$ coefficient was calculated according to the formula specified above. The area was determined on the figures with square segments of the internal split samples surfaces previously immersed in the chloride environment. 


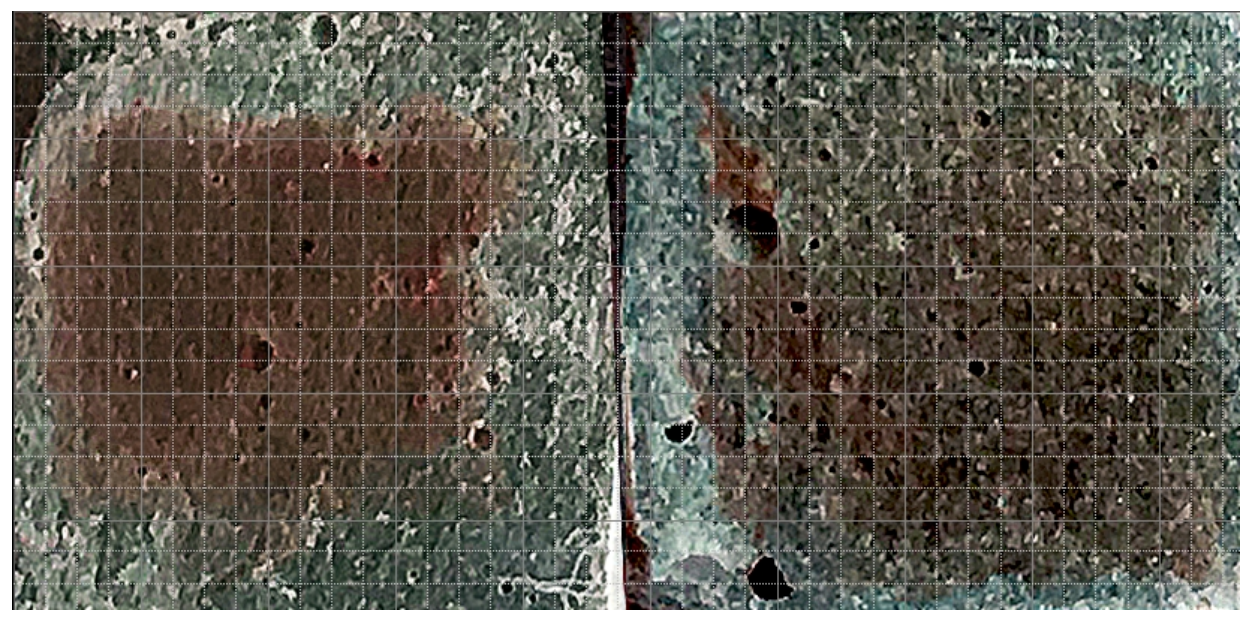

Fig. 1. Penetration depth of $5 \% \mathrm{NaCl}$ solution into the structure of Cement 1 (left) and Cement 2 (right) as a result of normal saturation for 2 days

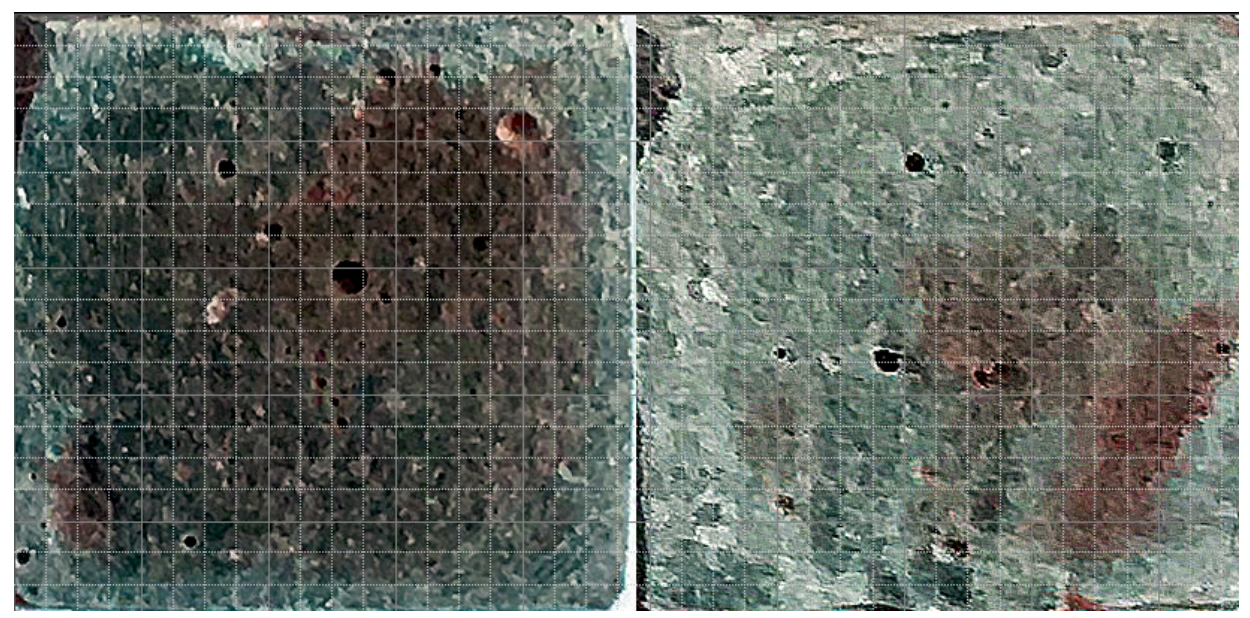

Fig. 2. Penetration depth of $5 \% \mathrm{NaCl}$ solution into the structure of Cement 1 (left) and Cement 2 (right) after 10 cycles of freezing-thawing

The colorimetric analysis showed that the chlorides penetration into the cement in both cases is very significant (light area in the figures), which creates a hazard for the reinforcement. It should be noted, that the area of Cement 1 (porosity 10.1\%) affected by chlorides is significantly greater than that of Cement 2 (porosity $12.2 \%$ ) for control samples saturated at room temperature. For these samples, there is a clear contrast boundary between the areas in the figures. While alternating freezing-thawing has a stronger impact on Cement 2, despite its greater frost resistance (a clear boundary hasn`t been observed, which is probably due to the reasons described above).

\section{Conclusions}

This work demonstrates that the problem of capillary-porous materials durability (cements) in the environment of aggressive chloride ions is still urgent. Solutions are the usage of mineral and chemical additives, regulation of the mineralogical composition (increase quantity of the aluminate phases), external surface treatment with water repellents, etc. The 
colorimetric method showed positive results. It is planned to compare the calculated and illustrative dates in near future. In conclusion, several points that significantly affect the quality of colorimetric chlorides determination should be noted: 1 . Determination of the free chlorides presence is recommended no later than 1-2 days after frost tests. Later tests do not give positive results due to the high activity of chloride ions and their ability to combine compounds rather quickly with cement phases (calcium hydroxide, aluminate phases); 2. It is necessary to maintain the $\mathrm{pH}$ of the surface layer which is analyzed in the region of 12-13, to avoid erroneous determination of the depth of carbonation; 3. Multicomponent colorimetric methods with fluoresceine and dichromate involving the usage of several reagents in our case did not show such accurate results comparing the usual method for determining with using $\mathrm{AgNO}_{3}$ solution only.

\section{References}

1. J. Stark, B. Wicht, Durability of concrete, edited by P. Krivenko. Kiev, Oranta (2004)

2. E. Potapova, Y. Krivoborodov, S. Samchenko, T. Kouznetsova, 18 International Multidisciplinary scientific Geoconference (SGEM 2018), v. 18, pp. 135-142 (2018)

3. E. Meck, V. Sirivivatnanon, Cement and Concrete Research, 33, pp. 1113-1117 (2004)

4. J.O. Ukpata, P.A.M. Basheer, L. Black, Construction and Binding Materials 195, pp. 238-248 (2019)

5. B. Dong, Y. Wu, X. Teng, Z. Zhuang, Z. Gu, J. Zhang, F. Xing, S. Hong, Construction and Binding Materials 211, pp. 261-270 (2019)

6. J. Yuan, Z. Du, Y. Wu, F. Xiao, Construction and Binding Materials 204, pp. 317-326 (2019)

7. F. He, C. Shi, Q. Yuan, C. Chen, K. Zheng, Construction and Binding Materials, 26, pp. 1-8 (2012)

8. STANDART 10060-2012 [RU] Concretes. Methods for determination of frostresistance (2012)

9. M. Collepardi, A. Marcialis, R. Turriziani, Cemento II, 67, pp. 157-164 (1970)

10. M. Kim, E. Yang, S. Yi, Construction and Building Materials, 41, 239-245 (2013)

11. L.V. Real, D.R.B. Oliveira, T. Soares, M. H. F. Medeiros, ALCONPAT Journal, 5(2), pp. 141-151 (2015)

12. E. Potapova, S. Sivkov, I. Korchunov, An ACI Technical Publication. Durability and Sustainability of Concrete Structures, SP-326, pp. 82.1-82.9 (2018)

13. E. Potapova, Y. Krivoborodov, S. Samchenko, T. Kouznetsova, MATEC Web of Conferences, «SMART City», 106, № 03026, pp. 15-17 (2016) 